\title{
P147 Association Between Inflammatory Markers of Low Intention and Arterial Stiffness
}

\author{
Daniele Brustolim ${ }^{1,2,3,}{ }^{*}$, Lucelia Magalhaes ${ }^{1,3}$, Yuri Oliveira Mariano ${ }^{2,3}$, Vinicius Louzada Castro ${ }^{4,3}$, \\ João Victor Perrone ${ }^{2}$, Joilson Jesus Barreto Júnior², Gabriela Valverde ${ }^{2}$ \\ ${ }^{1}$ Medical School, University Center of Science and Technology, Brazil \\ ${ }^{2}$ Bahian School of Medicine and Public Health, Salvador-Bahia, Brazil \\ ${ }^{3}$ Vascor Group, Salvador-Bahia, Brazil \\ ${ }^{4}$ Federal University of Bahia, Salvador-Bahia, Brazil
}

\section{ABSTRACT}

Extracellular and biochemical changes in the vessel contribute to the stiffening, this process is determinant for the increase of the Pulse Wave Velocity (PWV) and subsequent increase of the central and brachial arterial pressures $[1,2]$. These vascular alterations are denominated of TOD (target organ damage) and represent a point of association between cardiovascular risk factors and cardiovascular events [2,3]. Chronic low-grade inflammation associated with endothelial dysfunction and increased number of biomarkers, such as ultra-sensitive C-reactive protein (hsCRP), cytokines such as interleukins, fibrinogen, platelets, leukocytes and hematocrit $[4,5,6]$.

Methods: A cross-sectional exploratory study on a representative population of a community in Salvador-Bahia-Brazil. The data came from a including 301 individuals. 150 were initially assessed from December 2016 to May 2019. PWV measurement for the carotid-femoral by an ATCor SphygmoCor, data not demonstrated in this poster. Blood samples were collected to biochemistry analysis, ADVIA1800 (SiemensHealthcare Japan/Canada). The committee for research on human was done.

Results: The data show a predominance of women (65\%). Changes in leukocytes, platelets and hematocrit were more prevalent in men, as observed in Table 1. Mean values of changes in ultra-sensitive CRP values were higher in women $(0.43)$ than in men $(0,25)$.

Conclusion: Studies correlate the markers evaluated in this study as positive predictive factors for arterial stiffening. Data from the literature show these preliminary changes present in the male population, as observed in our population. The cytokines IL-1, 6 and 18, the chemokines MCP-1 and 3 and the adhesion molecules VCAM, ICAM are being evaluated to better respond to these findings.

Table 1

\begin{tabular}{lccc}
\hline & WBC & HEMATOCRIT & PLATELETS \\
\hline Column B vs Column A & WBC vs WBC & Ht WOMAN vs & $\begin{array}{c}\text { PLAT WOMAN vs } \\
\text { PLAT MAN }\end{array}$ \\
& & Ht MAN & \\
Unpaired $t$-test & & & 0.0337 \\
$p$-value & 0.0004 & 0.0246 & $*$ \\
$p$-value summary & Yes* & Yes & Yes \\
Significantly different $(p<0.05)$ ? & Two-tailed & Two-tailed & Two-tailed \\
One- or two-tailed $p$-value? & $t=4.840, d f=12$ & $t=2.980, d f=6$ & $t=2.397, d f=12$ \\
$t, d f$ & & & \\
How big is the difference? & 8950 & -3.567 & 311.3 \\
Mean of column A & 5767 & 3.167 & 250.2 \\
Mean of column B & $-3183 \pm 657.7$ & 1.197 & $-61.09 \pm 25.49$ \\
Difference between means $(\mathrm{B}-\mathrm{A}) \pm$ SEM & -4616 to -1750 & -6.496 to -0.6378 & -116.6 to -5.553 \\
$95 \%$ confidence interval & 0.6613 & 0.5968 & 0.3237 \\
$R$ squared (eta squared) & &
\end{tabular}

\section{REFERENCES}

[1] Tuttolomondo A, Pecoraro R, Di Raimondo D, Di Sciacca R, Canino B, Arnao V, et al. Immune-inflammatory markers and arterial stiffness indexes in subjects with acute ischemic stroke with and without metabolic syndrome. Diabetol Metab Syndr 2014;6:28.

[2] Maloberti A, Vallerio P, Triglione N, Occhi L, Panzeri F, Bassi I, et al. Vascular aging and disease of the large vessels: role of inflammation. High Blood Press Cardiovasc Prev 2019;26:175-82. 
[3] Arnold N, Gori T, Schnabel RB, Schulz A, Prochaska JH, Zeller T, et al. Relation between arterial stiffness and markers of inflammation and hemostasis - data from the population-based gutenberg health study. Sci Rep 2017;7:6346.

[4] Mozos I, Malainer C, Horbańczuk J, Gug C, Stoian D, Luca CT, et al. Inflammatory markers for arterial stiffness in cardiovascular diseases. Front Immunol 2017;8:1058.

[5] Gawaz M, Langer H, May AE. Platelets in inflammation and atherogenesis. J Clin Invest 2005;115:3378-84.

[6] Vinholt PJ, Hvas AM, Frederiksen H, Bathum L, Jørgensen MK, Nybo M. Platelet count is associated with cardiovascular disease, cancer and mortality: A population-based cohort study. Thromb Res 2016;148:136-42.

[7] Appiah D, Schreiner PJ, MacLehose RF, Folsom AR. Association of plasma $\gamma^{\prime}$ fibrinogen with incident cardiovascular disease: the atherosclerosis risk in communities (ARIC) study. Arterioscler Thromb Vasc Biol 2015;35:2700-6.

[8] Aliberti G, Proietta M, Pulignano I, Del Porto F, Tammeo A, Trappolini M. Association between fibrinogen plasma levels and platelet counts in an outpatient population and in patients with coronary heart disease. Blood Coagul Fibrinolysis 2010;21:216-20.

(C) 2019 Association for Research into Arterial Structure and Physiology. Publishing services by Atlantis Press International B.V. This is an open access article distributed under the CC BY-NC 4.0 license (http://creativecommons.org/licenses/by-nc/4.0/). 